\title{
Impact of Macroeconomic Variability on the Stock Market Volatility of Bangladesh
}

Mostafa Ali a,

a University of Chittagong, Bangladesh, mostafacu20oo@gmail.com, https://orcid.org/0000-0003-2496-2960

ARTICLE INFO

Research Article

2021, Vol. 3(2), 66-86

e-ISSN 2667-5927

Article History:

Received: 12.08 .2020

Revised: 30.12 .2020

Accepted: 08.01.2021

Available Online: 30.04.2021

JEL Code: $\quad$ C32, C58, E44
Impact of Macroeconomic Variability on the Stock Market Volatility of Bangladesh

Abstract

This study investigates the impact of macroeconomic variability on stock market volatility in Bangladesh covering the data ranging from January 2005 to December 2018 by using three steps of analysis. Firstly, the univariate Exponential Generalized Autoregressive Conditional Heteroskedasticity (EGARCH) model is employed to estimate the time-varying conditional variance series for stock return and macroeconomic fundamentals. In the second phase, the volatility effect of macroeconomic forces on stock return is estimated by using the most recent standardized squared residuals of macroeconomic fundamentals as exogenous variables in the conditional variance equation of stock returns. Finally, Vector Auto Regression (VAR) model is used to examine the possible interaction between macroeconomic forces and stock price. The findings of the study evidence that increased volatility in Consumer Price Index, Treasury Bill Rates, and inflow in Foreign Remittance increases the stock return volatility whilst fluctuations in IP leads to a decrease in stock return volatility. Therefore, the implication of these findings documents that both the stock market and macroeconomic forces becoming interdependent in Bangladesh.

To cite this document: Ali, M. (2021). Impact of Macroeconomic Variability on the Stock Market Volatility of Bangladesh. BILTURK, The Journal of Economics and Related Studies, 3(2), 66-86. doi: 10.47103/bilturk.837413
Keywords: macroeconomic variability, stock market volatility, egarch model, VAR model, bangladesh. 


\section{Introduction}

Variability about the macroeconomic forces is momentous for the financial market volatility because it is evident from the existing literature that new information about the economy matters for the financial market. Therefore, volatility in the financial market should be connected to the uncertainty about the state of the economy. Moreover, stock pricing factors volatility is significantly related to macroeconomic volatility (Chen et al., 2017). Since, investors are risk-averse, excessive volatility, and hence riskiness erodes investors' confidence (Tokmakcioglu and Tas, 2014). It restricts the smooth functioning of the capital market and fair pricing of securities. It could give significant information to the market players in allocating their investment. Empirical studies such as Fama, 1981, 1990; Chen et al., 1986; Paye, 2012; Corradi et al. 2013; Kumari and Mahakud, 2015; Nikmanesh and Nor, 2016, among others have documented that volatility in the macroeconomic forces is the major determinant of the stock market volatility. Moreover, macroeconomic fundaments help to determine the cash flows and overall risk of the firm and therefore the stock price. Relevant financial and economic theories also suggest a close relation exists between stock market volatility and macroeconomic uncertainty. In a classical study, Schwert (1989) states that,

"If macroeconomic data provide information about the volatility of either future expected cash flows or future discount rates, they can help explain why stock return volatility changes over time."

An appropriate measure of future volatility is crucial for asset allocation and risk management (Asgharian et al., 2013). Macroeconomic information helps market participants and analysts to manage their portfolios properly (Adjasi, 2009). Chowdhury and Rahman (2004) pointed that innovation or shock in macroeconomic fundamentals will drive to increase the unsystematic and systematic risk of the market portfolio, it is no matter whether the portfolio is well diversified or not.

Studying the relations between stock market volatility and macroeconomic forces has some important implications for the investors and the policymakers. For investors, the knowledge of macroeconomic volatility and stock price volatility could help them to accurately predict stock price movements and better manage the investment portfolio. It also enables them to set up profit-maximizing investment and hedging strategies. Such information also assists policymakers to take appropriate policy action that promises macroeconomic and financial stability.

In the context of the explanatory ability of the macroeconomic fundamentals in determining the stock price volatility are mixed. One group of empirical works (for example, Roll, 1988; Cutler et al., 1989; Schwert, 1989; Zakaria and Shamsuddin, 
2012) argues that the explanatory power is weak; whereas the other group (such as Corradi et al., 2013; Nikmanesh and Nor, 2016) suggests that it is strong. It is noted here that these empirical studies differ methodologically from each other. In the first group, Roll (1988) used the regression model, Cutler et al. (1989) and Schwert (1989) utilized Vector Autoregressions (VAR) model while Zakaria and Shamsuddin, (2012) employed two steps of analysis. In the first step, Zakaria and Shamsuddin, (2012) used the $\operatorname{GARCH}(1,1)$ model to estimate the variance series of stock return and macroeconomic fundamentals and in the second phase, bivariate and multivariate VAR model is employed to uncover the linkage between stock market volatility and macroeconomic uncertainties. In the second group, Corradi et al. (2013) developed a no-arbitrage model whereas Nikmanesh and Nor (2016) used the GARCH family of models to estimate the variance series in the first step of analysis and then employed the Seemingly Unrelated Regression (SUR) methodology to detect whether there is an association between stock return variability and macroeconomic uncertainty.

Therefore, to contribute to the literature and this debate, this piece of work examines the influence of macroeconomic uncertainty on stock market volatility by using three steps of analysis. Firstly, the univariate EGARCH model is employed to estimate the time-varying conditional variance series for stock return and macroeconomic fundamentals. In the second phase, we use the methodology motivated by that of Hamao et al. (1990), Kanas and Kouretas (2001), Erdem et al. (2005, and Adjasi (2009) to test the effect of macroeconomic volatility on stock price volatility. In the third phase, Vector Auto Regression (VAR) model is used to examine the possible interaction between macroeconomic forces and stock price.

The structure of the remainder of the paper is as follows. Section 2 outlines the literature review of the study. Section 3 describes the relevant data and variables while Section 4 explains the methodology used in this study. The empirical results and analysis are presented in Section 5, and finally, Section 6 concludes the paper.

\section{Literature Review}

Prior studies used different macroeconomic factors to explain the stock price volatility. These macroeconomic variables are similar but segregated. Tangjitprom (2012) classified the macroeconomic variables used in prior studies into four groups. The first group includes variables related to general economic conditions, namely industrial production, employment level. The second group of variables involving interest rates and monetary policy, such as interest rates, term spread, and default spread. The third group of variables representing the price level, including consumer price index, crude oil price, gold price, and the final group focus on variables that explain global activities, such as exchange rate, international trade, and foreign direct investment. 
Mittnik et al. (2015) employed component-wise boosting techniques to a wide range of potential risk drivers to detect the influence of S\&P 500 returns volatility and documented that the selected risk drivers influence the future volatility in a nonlinear fashion. Beetsma and Giuliodori (2012) reported that macroeconomic response to stock market volatility shock changed significantly over time. Park et al. (2017) investigated the stock market returns and implied volatility of the Korean Stock Market by using VAR-DCC-MGARCH-class of models and reported that the Korean Won-US Dollar exchange rate has a substantial impact on the conditional correlation between stock return and volatility. Their empirical finding also revealed that the risk-free interest rate has a marginal effect on the conditional correlation between stock return and volatility.

Garza-Garcia and Yue (2010) documented that the macroeconomic environment of China can be better explained by the Shanghai Composite Index and that the US macroeconomic forces have a positive influence on Chinese stock indices. By using the canonical correlation analysis, Mazuruse (2014) also reported that the selected macroeconomic indicators significantly influence maximizing the Zimbabwean stock returns. Moreover, Kabir et al. (2014) found the existence of a significant relationship between Malaysian stock prices, exchange rates, and the S\&P 500 index. Kan and Lim (2015) uncovered the impact of local and foreign indicators on Malaysian stock price. Their study evident that Malaysian stock prices increase with the increase of inflation and US stock price but it decreases with the increase of industrial production and money supply in the long-run. In the short-run, no macroeconomic indicators significantly influence Malaysian stock prices.

Hsing and Hsieh (2012) employed the GARCH or ARCH model to investigate the influences of macroeconomic fundamentals on Poland's stock market index. Their empirical study showed that a higher German or the US stock market index, an increase in industrial production or real GDP, less government borrowing, decrease in Treasury bill rate, depreciation in exchange rate, lower inflation, a lower euro area government bond yield, and decrease in M2/GDP ratio have positive influence on Poland stock market index. By using the same econometric methodology, Hsing (2011) also documented that the Bulgarian stock market rise with the increase in real GDP, higher M2/GDP ratio, a decrease in the interest rate or inflation rate, lower ratio of government deficit to GDP, the bullish trend in US stock market and decrease in the euro area government bond yield.

Kumari and Mahakud (2015) investigated whether there were any relations between the conditional volatility of domestic macroeconomic forces and stock market volatility in India and found a significant relationship between selected macroeconomic fundamentals and stock market volatility. The findings of the study also documented that financial markets and macroeconomic variables in India becoming more and more interdependent. Aliyu (2012) employed the quadratic 
GARCH model to explore the asymmetric volatility effect in the Nigerian and Ghanaian stock market and evident that negative innovation has more impact on the stock market volatility than the positive shocks of equal magnitude in Nigeria while for Ghana, the opposite is true. Moreover, their empirical study reported that inflation is a significant determinant of stock market volatility in both countries. Jain and Biswal (2016) employed the DCC-GARCH class of models and non-linear causality test to uncover the relationship between global crude oil price, gold price, exchange rate, and Sensex. The empirical findings of the study disclosed that a decline in the global gold and crude oil prices lead to a depreciation in the Indian rupee and hence decrease the Sensex. By employing the EGARCH model, the study of Nguyen and Ngo (2014) found a stronger relationship between US macroeconomic conditions and Asian stock market returns and reported that changes in the US macroeconomic announcements influence in conditional mean and variance of the Asian stock market returns.

Abbas et al. (2019) found a strong linkage between the returns and volatilities of stock markets and selected macroeconomics variables in the G-7 economies. By using the VECM and EGARCH model, Fernando (2018) investigated the impact of macroeconomic uncertainty on stock market volatility in the Sri Lankan stock market and found a long run relationship between selected macroeconomic forces and stock returns. Moreover, the findings of the study evidence the existence of asymmetric volatility in the stock returns. The study also documented that interest rate and exchange rate volatility increase the stock returns volatility in Sri Lanka. Dayıoğlu and Aydın (2019) reported that exchange rate and industrial production index volatility significantly affect the Turkish stock market volatility. Baroian (2014) reported that exchange rate volatility significantly explains the stock market volatility of five selected Central and Eastern European economies. On the contrary, Karim et al. (2014) documented that stock market volatility leads to exchange rate volatility in Indonesia.

\section{Data and Variables}

The objective of this study is to explore the impact of macroeconomic variability on stock market volatility in Bangladesh by using monthly data from January 2005 to December 2018. Monthly closing prices of the DSE general index (DSEX) are used to measure the stock market returns of Bangladesh. Consulting with the existing literature, we choose a comprehensive set of macroeconomic variables like industrial production index (IP), consumer price index (CPI), broad money supply $(\mathrm{M} 2)$, 91-day treasury bill rate (TB), treasury bond yield (GB), exchange rate (EX) and inflow of foreign remittance (RT).

By using the following technique, DSEX is converted into compounded monthly returns:

$\mathbf{R}_{M t}=\ln \left(\mathbf{P}_{t}\right)-\ln \left(\mathbf{P}_{t-1}\right)$ 
Where RMt is the stock market return in month $t$, In is the natural logarithm, Pt is the ending value of DSEX at month t, Pt-1 is the Previous month's closing value of DSEX.

Same logarithmic transformation is employed to all other macroeconomic fundamentals to convert them into growth series. DSEX data series is collected from the official website of the Dhaka Stock Exchange (DSE) Limited. Data series of M2 and RT are collected from the different volumes of Monthly Economic Trends, a monthly bulletin published by the Statistic Department of Bangladesh Bank (BB). The rest of the data series namely IP, CPI, TB, GB are obtained from the International Financial Statistics (IFS) of the International Monetary Fund (IMF).

\section{Methodology}

This study attempts to explore the effect of macroeconomic variability on stock return volatility. Therefore, it is appropriate to use volatility models. The technique of analysis is in three phases. Firstly, the exponential generalized autoregressive conditional heteroskedasticity (EGARCH) model introduced by Nelson (1991) is applied to estimate the volatility of each of the variables of interest. This model is used because it can better capture the asymmetric effect of shocks on conditional volatility and to avoid imposing non-negativity restrictions on the GARCH parameters to be estimated. The conditional mean and variance specification of $\operatorname{EGARCH}(p, q)$ can be written as follows:

$\mathbf{R}_{t}=\alpha_{0}+\sum_{\mathrm{i}=1}^{\mathrm{r}} \boldsymbol{\alpha}_{1} \mathbf{R}_{t-i}+\epsilon_{t}$

Where $\epsilon_{t} \backslash \Omega_{t-1} \sim \mathbf{N}\left(0, h_{t}\right)$ and

$\log \left(\mathbf{h}_{t}\right)=\mathrm{a}_{\mathbf{0}}+\sum_{\mathrm{i}=\mathbf{1}}^{\mathbf{p}} \boldsymbol{\beta}_{i} \log \left(\mathbf{h}_{t-i}\right)+\sum_{\mathbf{i}=\mathbf{1}}^{\mathbf{q}} \mathrm{a}_{i}\left[\left|\frac{\varepsilon_{t-i}}{\sqrt{\mathbf{h}_{t-i}}}-\mathbf{E}\left(\frac{\varepsilon_{t-i}}{\sqrt{\mathbf{h}_{t-i}}}\right)\right|\right]+\sum_{\mathrm{i}=1}^{\mathbf{m}} \gamma_{i} \frac{\varepsilon_{t-i}}{\sqrt{\mathbf{h}_{t-i}}}$

Where Rt represents the series of stock market returns and macroeconomic variables at time $t, \alpha 0$ is the mean value of series, $\epsilon t$ denotes the stochastic error term which is conditional on a previous information set, $\Omega \mathrm{t}-1$, and is assumed to be normally distributed with a zero mean and variance ht.

In the conditional mean equation (equation 2), an autoregressive process of order $r$ [i.e., $A R(r)$ ] is added in each series to whiten the error term (since Ljung-Box statistics of most of the series were statistically significant evidencing the existence of autocorrelation in the series).

The conditional variance equation (equation 3) presents the $\operatorname{EGARCH}(p, q)$ specification which states that conditional variance depends not only on standardized residuals but also on its own variance in the previous time periods. The persistence of volatility is measured by $\sum_{\mathrm{i}=1}^{\mathrm{p}} \beta_{i}<1$. $\gamma_{\mathrm{i}}$ denotes asymmetric 
coefficient and is also known as the leverage effect parameter. The impact is asymmetric if $\gamma \neq 0$. The existence of the leverage effect is tested by the hypothesis that $\gamma<0$. When $\gamma<0$ good news (positive shocks) produce less volatility than bad news (negative shocks). Likelihood ratio (LR) tests are employed to determine the lag truncation lengths for EGARCH models.

In the second phase, we follow the similar methodology used by Hamao et al. (1990), Kanas and Kouretas (2001), Erdem et al. (2005), Adjasi (2009) to test the volatility effect of macroeconomic forces on stock prices. These empirical studies utilized the most recent squared residuals as exogenous variables which were derived from the EGARCH models of macroeconomic fundamentals in the conditional variance equation of stock price. Therefore, to examine the volatility effect of macroeconomic variables on stock price, we introduce the squared residuals series of industrial production, consumer price index, money supply, Treasury bill, government bond, exchange rate, and foreign remittance as an exogenous variable in the conditional variance equation of DSEX. Thus, the conditional variance equation for DSEX takes the following form:

$$
\begin{aligned}
& \log \left(\mathbf{h}_{\text {DSEX,t }}\right)=a_{0}+\beta_{1} \log \left(\mathbf{h}_{D S E X, t-1}\right)+a_{1}\left[\left|\frac{\varepsilon_{D S E X, t-1}}{\sqrt{\mathbf{h}_{D S E X, t-1}}}-\mathrm{E}\left(\frac{\varepsilon_{D S E X, t-1}}{\sqrt{\mathbf{h}_{D S E X, t-1}}}\right)\right|\right]+ \\
& \gamma \frac{\varepsilon_{D S E X, t-1}}{\sqrt{\mathbf{h}_{D S E X, t-1}}}+\lambda_{1} \log \left(\mathbf{U}_{\text {ip }, t}\right)+\lambda_{2} \log \left(\mathbf{U}_{c p i, t}\right)+\lambda_{3} \log \left(\mathbf{U}_{m 2, t}\right)+\lambda_{4} \log \left(\mathbf{U}_{t b, t}\right)+ \\
& \lambda_{5} \log \left(\mathbf{U}_{g b, t}\right)+\lambda_{6} \log \left(\mathbf{U}_{e x, t}\right)+\lambda_{7} \log \left(\mathbf{U}_{r t, t}\right)
\end{aligned}
$$

Where $U_{i p, t}, U_{c i p, t}, U_{m 2, t}, U_{t b, t}, U_{g b, t}, U_{e x, t}, U_{r t, t}$ are the contemporaneous standardized squared residuals from the best-fitted EGARCH models for industrial production, consumer price index, money supply, treasury bill, government bond, exchange rate, and foreign remittance respectively, and $\frac{\varepsilon_{D S E X, t-1}}{\sqrt{\mathrm{h}_{D S E X, t-1}}}$ is the lagged standardized residuals for DSEX. The presence of volatility effect from macroeconomic variables on stock price is estimated by the statistical significance of $\lambda_{1}$ through $\lambda_{7}$. Susmel and Engel (1994) reported that conventional standard errors of the parameters in the conditional variance equation tend to underestimate the true standard errors. Therefore, statistical inference regarding parameters (i.e., parameters $\lambda_{1}$ through $\lambda_{7}$ ) is based on GED robust standard errors of Bollerslev and Wooldridge (1992) to allow for probable violations of normality in the conditional errors.

Assuming conditional normality for price returns in each equation and applying the $\mathrm{BHHH}$ algorithm proposed by Berndt et al. (1974), the log-likelihood function for the EGARCH model is estimated by:

$$
L(\Theta)=\left(\frac{-T}{2}\right) \log (2 \pi)-0.5 \sum_{t=1}^{T} \log \left(h_{t}\right)
$$

Where $\Theta$ is the parameter vector $\left(\alpha_{0}, \alpha_{1}, \alpha_{2}, a_{0}, a_{1}, \beta_{1}, \lambda_{1}, \lambda_{2}, \lambda_{3}, \lambda_{4}, \lambda_{5}, \lambda_{6}, \lambda_{7}\right)$ and $T$ is the sample observations. It is noted that the $\mathrm{BHHH}$ algorithm is utilized to maximize $L(\Theta)$. 
In the third phase, this study employs a Vector Auto Regression (VAR) model proposed by Sims (1980). There are some advantages of using the VAR model. Firstly, it imposes a very minor restriction. Secondly, it is a simultaneous equation model having more than one dependent variable. Finally, discrimination is not made between endogenous and exogenous variables even though simultaneity is found among a number of variables.

The multivariate VAR model is articulated as follows:

$$
\begin{aligned}
& \operatorname{hDSEX}_{t}=\Pi_{0}+\sum_{\mathrm{i}=1}^{\mathrm{P}} \boldsymbol{\vartheta} \mathbf{h D S E X}_{t-i}+\sum_{\mathrm{i}=1}^{\mathrm{p}} \rho \mathbf{h m v}_{j t-i}+\varepsilon_{t} \\
& \mathbf{h m v}_{t}=\Gamma_{0}+\sum_{\mathbf{i}=1}^{\mathrm{p}} Q \mathbf{h m v}_{j t-i}+\sum_{\mathrm{i}=1}^{\mathrm{p}} \partial \mathbf{h D S E X}_{t-i}+\varepsilon_{t}
\end{aligned}
$$

Where $h D S E X_{t}$ represents the conditional volatility of stock price at time $t, h m v_{t}$ designates the conditional volatility of macroeconomic variable $j$ at time $t, i$ is the lag length. $\theta$ and $\partial$ denote the lagged values of the conditional volatility of DSEX whereas $\rho$ and $\boldsymbol{Q}$ designate the coefficient of lagged values of the conditional volatility of macroeconomic variable $j$.

But, when a large number of coefficients involved, the use of the VAR structure creates a problem to interpret the results. To overcome this limitation, it is estimated by using a set of statistics such as block exogeneity, variance decompositions, and impulse response functions. In this study, we use variance decomposition and impulse response analysis along with the VAR model.

\subsection{Variance Decomposition (VDC)}

Variance decomposition is an appropriate tool to deal with the dynamic stochastic process under the VAR environment. It exhibits the proportion of movement in the dependent variable that is due to its own shocks as well as shocks for the other variables. Hence, an innovation to a particular variable (say ith variable) will directly influence that variable but it will also be transmitted to other variables in the system. In other words, it splits the forecast error variance for each variable into parts to ascertain the effect of exogeneity of variables involved in the system over the different period of time. Therefore, the degree of exogeneity of the variables can be determined by employing VDC techniques. Empirical studies suggest that most of the forecast error variance is explained by the own series innovations rather than the shocks from other series. Therefore, it is anticipated that conditional stock price (return) volatility will be elucidated by its own innovations rather than the shocks and innovation from other macroeconomic fundamentals.

\subsection{Impulse Response Function (IRF)}

The IRF explores the response of one-unit shock of a dependent variable to one standard error shock to each of the other variables in the VAR structure. We use 
this technique in this study to capture the sign, magnitude, and persistence of responses of one market to shocks in another stock market. The IRF is estimated by using the Cholesky decomposition method since it does not require orthogonalization of innovations and does not differ with the ordering of variables in the VAR model.

\section{Empirical Results and Analysis}

Descriptive statistics for the stock return and growth series of macroeconomic variables are reported in Table 1. The measure of skewness exhibits that the growth series of DSEX, IP, TB, GB, and RT are negatively skewed while the rest of the variables are positively skewed. All of the variables are leptokurtic relative to the normal distribution. Normality is rejected in all the series except RT based on the Jarque-Bera (JB) test statistics. Significant autocorrelation is identified based on the LB test implies the volatility clustering in the growth series of the variables.

Table 1: Descriptive Statistics

\begin{tabular}{lllllllll}
\hline \hline & DSEX & IP & CPI & M2 & TB & GB & EX & RT \\
\hline \hline Mean & 0.007 & 0.010 & 0.005 & 0.014 & -0.003 & -0.002 & 0.002 & 0.009 \\
Median & 0.009 & 0.015 & 0.005 & 0.013 & 0.000 & 0.000 & 0.000 & 0.002 \\
Maximum & 0.264 & 0.201 & 0.043 & 0.049 & 0.958 & 0.187 & 0.047 & 0.462 \\
Minimum & -0.351 & -0.267 & -0.014 & -0.021 & -1.141 & -0.217 & -0.026 & -0.377 \\
SD & 0.078 & 0.079 & 0.009 & 0.011 & 0.163 & 0.049 & 0.009 & 0.136 \\
Skewness & -0.693 & -0.715 & 0.223 & 0.237 & -0.508 & -0.447 & 2.759 & -0.056 \\
Kurtosis & 7.185 & 4.497 & 3.883 & 3.895 & 27.951 & 11.293 & 15.361 & 3.678 \\
Jarque- & 118.643 & 27.391 & 9.743 & 10.019 & 3515.81 & 519.335 & 1079.11 & 3.975 \\
Bera & & & & & & & & \\
Prob. & 0.000 & 0.000 & 0.048 & 0.037 & 0.000 & 0.000 & 0.000 & 0.197 \\
LB(10) & 29.915 & 66.435 & 73.255 & 29.355 & 15.711 & 27.794 & 31.525 & 67.341 \\
Prob. & 0.000 & 0.000 & 0.000 & 0.002 & 0.275 & 0.017 & 0.021 & 0.000 \\
\hline \hline
\end{tabular}

Correlation between stock return and selected macroeconomic forces are reported in Table 2.

Table 2: Correlation Matrix of stock return and macroeconomic variables

\begin{tabular}{|c|c|c|c|c|c|c|c|c|}
\hline & DSEX & IP & CPI & M2 & TB & GB & EX & RT \\
\hline$\overline{\text { DSEX }}$ & 1.00 & & & & & & & \\
\hline IP & -0.01 & 1.00 & & & & & & \\
\hline CPI & -0.08 & $-0.26 * *$ & 1.00 & & & & & \\
\hline $\mathrm{M} 2$ & $0.29 *$ & $0.32^{*}$ & 0.01 & 1.00 & & & & \\
\hline TB & -0.08 & -0.07 & 0.14 & -0.03 & 1.00 & & & \\
\hline GB & -0.12 & 0.02 & -0.08 & 0.12 & $0.26 *$ & 1.00 & & \\
\hline EX & $-0.15 * * *$ & 0.12 & -0.08 & -0.05 & $0.18^{* * *}$ & 0.06 & 1.00 & \\
\hline RT & 0.01 & $0.58^{*}$ & -0.06 & $0.33^{*}$ & -0.05 & 0.12 & $0.29 *$ & 1.00 \\
\hline
\end{tabular}


The correlation between IP, CPI, TB, GB, and EX are found to be negative but it is found positive for M2 and RT. Contrary to the economic theory and prior literature, the sign of correlation coefficient between stock return (DSEX) and IP as well as DSEX and CPI is negative whereas all other relations between stock return and macroeconomic forces are found consistent with existing literature and economic theory.

Because of the non-stationary nature of the time series data, it is important to examine the stationarity or otherwise of the data series. For this purpose, we employed the Augmented Dickey-Fuller (1981) (ADF) and Kwiatkowski, Phillips, Schmidt, and Shin (1992) (KPSS) stationarity test. ADF test hypothesized the existence of unit root whereas null of stationarity in the series were scrutinized by KPSS test. The result of the stationarity tests are reported in Table 3 and indicate that stock returns and growth series of selected macroeconomic fundamentals are stationary at level.

Table 3: Results of the Stationarity Test

\begin{tabular}{llllll}
\hline \hline Variables & \multicolumn{2}{l}{$\begin{array}{l}\text { Augmented } \\
\text { (ADF)Test Statistic }\end{array}$} & $\begin{array}{l}\text { Dickey } \\
\text { (ADuller }\end{array}$ & \multicolumn{2}{l}{ Kwiatkowski-Phillips-Schmidt- } \\
& Constant & Constant \& & Constant & Constant & \& \\
& & Trend & Const Static & \\
DSEX & $-12.792^{*}$ & $-12.778^{*}$ & 0.143 & 0.094 \\
IP & $-5.175^{*}$ & $-5.133^{*}$ & 0.113 & 0.099 \\
CPI & $-2.967^{*}$ & $-3.411^{* * *}$ & 0.151 & 0.075 \\
M2 & $-4.059^{*}$ & $-4.738^{*}$ & 0.331 & 0.115 \\
TB & $-11.942^{*}$ & $-11.751^{*}$ & 0.109 & 0.061 \\
GB & $-4.927^{*}$ & $-4.967^{*}$ & 0.327 & 0.106 \\
EX & $-8.174^{*}$ & $-8.222^{*}$ & 0.207 & 0.088 \\
RT & $-14.762^{*}$ & $-8.751^{*}$ & 0.291 & 0.112 \\
Critical values of test statistic & & & \\
At 1\% & -3.477 & -4.024 & 0.739 & 0.216 \\
At 5\% & -2.881 & -3.442 & 0.463 & 0.146 \\
At 10\% & -2.578 & -3.145 & 0.347 & 0.119 & \\
\hline \hline
\end{tabular}

Lag length for ADF test statistic was determined by using AIC whereas the bandwidths for KPSS test statistic was selected by considering Newey-West automatic suggestion following Bartlett Kernel estimation. $*, * * \& * * *$ designate acceptance of alternative hypothesis at $1 \%, 5 \%$ and $10 \%$ level respectively.

It was found that the error term of the mean equations of the series became uncorrelated after adding two autoregressive components in $\mathrm{CPI}, \mathrm{M} 2, \mathrm{~GB}$ series and one autoregressive term in the rest of the series. Moreover based on the minimum values of AIC and SIC, the significant value of the model parameters as well as the diagnostic test, the best-fit EGARCH models were determined which were reported in Table 4. 
Ali, M. (2021). Impact of Macroeconomic Variability on the Stock Market Volatility of Bangladesh. BILTURK, The Journal of Economics and Related Studies, 3(2), 66-86. doi: 10.47103/bilturk.837413.

Table 4: Best-fit EGARCH model

\begin{tabular}{cc}
\hline \hline Variable & Model \\
\hline \hline DSEX & $\operatorname{AR}(1)-\operatorname{EGARCH}(1,1)$ \\
IP & $\operatorname{AR}(1)-\operatorname{EGARCH}(1,1)$ \\
CPI & $\operatorname{AR}(2)-\operatorname{EGARCH}(2,2)$ \\
M2 & $\operatorname{AR}(2)-\operatorname{EGARCH}(1,2)$ \\
TB & $\operatorname{AR}(1)-\operatorname{EGARCH}(1,2)$ \\
GB & $\operatorname{AR}(2)-\operatorname{EGARCH}(2,2)$ \\
EX & $\operatorname{AR}(1)-\operatorname{EGARCH}(2,2)$ \\
RT & $\operatorname{AR}(1)-\operatorname{EGARCH}(1,1)$ \\
\hline \hline
\end{tabular}

The estimates of the univariate AR $(r)-\operatorname{EGARCH}(p, q)$ models for each of the series are presented in Table 5 . Volatility persistence as measured by $\beta i$ is evidence in stock returns and all the growth series of macroeconomic variables except for IP and $\mathrm{GB}$. The ARCH effect parameters (as measured by ai) are found significant in all the growth series of macroeconomic variables but it is insignificant in DSEX.

Table 5: Results of the AR(r)-EGARCH(p,q) model

\begin{tabular}{|c|c|c|c|c|c|c|c|c|}
\hline $\begin{array}{c}\text { Coefficien } \\
t\end{array}$ & $\begin{array}{c}\text { DSEX(1,1 } \\
)\end{array}$ & IP $(1,1)$ & $\begin{array}{c}\text { CPI (2, } \\
2)\end{array}$ & $\mathrm{M} 2(1,2)$ & TB $(1,2)$ & $\mathrm{GB}(2,2)$ & $\operatorname{EX}(2,2)$ & $\begin{array}{c}\text { RT (1, } \\
\text { 1) }\end{array}$ \\
\hline$\alpha_{1}$ & $0.243^{* * *}$ & $-0.522^{*}$ & $0.388^{*}$ & $-0.550 *$ & $0.049 *$ & $0.059 *$ & $-0.153^{*}$ & $-0.296^{*}$ \\
\hline$\alpha_{2}$ & -- & -- & $-0.189 * *$ & $-0.062^{*}$ & -- & $0.038^{*}$ & -- & -- \\
\hline \multicolumn{9}{|c|}{ Variance Equation } \\
\hline$a_{0}$ & -7.792 & $-6.380^{*}$ & $-23.514^{*}$ & $-5.532^{*}$ & $-0.200 *$ & $-6.802 *$ & $-9.891 *$ & 0.121 \\
\hline $\mathrm{a}_{1}$ & 0.142 & 0.255 & 0.041 & $-1.151 *$ & $-0.650^{*}$ & $-1.229 *$ & $2.704^{*}$ & $\begin{array}{c}0.222^{*} \\
*\end{array}$ \\
\hline$a_{2}$ & -- & -- & $0.968^{* *}$ & -- & -- & $-0.589 *$ & $3.453^{*}$ & -- \\
\hline$\beta_{1}$ & $-0.473^{*}$ & -0.208 & $-0.633^{*}$ & $0.766^{*}$ & $-0.056^{*}$ & 0.019 & $-0.206^{*}$ & 0.941 \\
\hline$\beta_{2}$ & -- & -- & $-0.735^{*}$ & $-0.430^{*}$ & $0.932^{*}$ & $0.051 * *$ & $0.795^{*}$ & -- \\
\hline$\gamma$ & $-0.280^{*}$ & $0.493^{*}$ & $0.353^{*}$ & $0.718^{*}$ & $-1.425^{*}$ & $-1.782^{*}$ & $0.577^{*}$ & -0.109 \\
\hline $\mathrm{LL}$ & 168.176 & $\begin{array}{c}185.22 \\
9\end{array}$ & 313.836 & 301.889 & 145.796 & 243.807 & 418.859 & 96.697 \\
\hline \multicolumn{9}{|c|}{ Diagnostic tests } \\
\hline LB (10) & 7.2449 & $\begin{array}{c}92.731 \\
*\end{array}$ & $\begin{array}{c}19.780 * \\
*\end{array}$ & 9.119 & 9.320 & 7.138 & $\begin{array}{c}12.036^{* *} \\
*\end{array}$ & 6.076 \\
\hline $\operatorname{LB}^{2}(10)$ & 1.5826 & 4.8258 & 7.239 & $\begin{array}{c}16.860 * * \\
*\end{array}$ & 6.162 & 2.298 & 14.027 & 13.228 \\
\hline$J B$ & $16.085^{*}$ & $\begin{array}{c}6.292^{*} \\
*\end{array}$ & 2.541 & 3.843 & $\begin{array}{c}213.378 \\
*\end{array}$ & $\begin{array}{c}588.849 \\
*\end{array}$ & 1.952 & 0.762 \\
\hline $\mathrm{ARCH}(10)$ & 0.002 & 0.019 & 0.724 & $2.055^{* *}$ & 0.462 & 0.173 & 1.196 & 1.148 \\
\hline
\end{tabular}

Note: $*, * *$ and $* * *$ represent the significance at $1 \%, 5 \%$ and $10 \%$ respectively. $a_{0}$ stands for the constant value of Variance equation, $\alpha, \beta$ and $\gamma$ represent the ARCH term, GARCH term, and leverage term respectively. $\alpha+\beta$ indicate the stationary condition of the GARCH model, $L L$ represents the Log-likelihood, $L B(10)$ and $L^{2}(10)$ indicate the Ljung-Box statistics for standardized residuals and squared standardized residuals using 10 lags respectively, JB denotes Jarque-Bera test statistic, ARCH represents the ARCH-LM test for heteroscedasticity. 
The significant values of ARCH and GARCH terms imply that the lagged values of the error terms and the lagged values of conditional volatility can better capture the future volatility. The coefficient $\gamma$ (asymmetric effect parameter) is significant in all the series except for RT. The signs of asymmetric effect parameter are negative for DSEX and for both interest rates which indicate that negative innovation has a higher impact on conditional volatility than those of the positive innovation of the equal magnitude. On the other hand, positive signs are evident for IP, CPI, M2, and EX suggesting the positive shock would lead to a higher next period conditional volatility than the negative shock of the same magnitude. Most of the post estimation test results such as LB (10), LB2 (10), Jarque-Bera (JB), and ARCH-LM (10) evidence that the EGARCH models are robustly specified in each of the series.

\begin{tabular}{ccccc}
\multicolumn{5}{l}{ Table 6: Results of univariate AR (1)-EGARCH } \\
\multicolumn{5}{c}{$\begin{array}{c}(1,1) \\
\text { effect }\end{array}$} \\
\hline \hline Parameters & Coefficient & Standard error & $\begin{array}{c}\text { Robust } t \text { - } \\
\text { statistic }\end{array}$ & Probability \\
\hline \hline$\alpha$ & 0.211 & 0.029 & 7.192 & 0.000 \\
Variance Equation & & & & \\
$\mathrm{a}_{0}$ & -10.101 & 0.324 & -31.171 & 0.000 \\
$\mathrm{a}_{1}$ & 0.958 & 0.197 & 4.871 & 0.000 \\
$\beta_{1}$ & -0.562 & 0.051 & -11.018 & 0.000 \\
$\gamma$ & -0.762 & 0.130 & -5.879 & 0.000 \\
IP & -0.198 & 0.078 & -2.524 & 0.011 \\
CPI & 0.354 & 0.062 & 5.715 & 0.000 \\
M2 & 0.018 & 0.073 & 0.251 & 0.802 \\
TB & 0.100 & 0.017 & 5.914 & 0.000 \\
GB & 0.057 & 0.056 & 1.027 & 0.305 \\
EX & 0.117 & 0.113 & 1.038 & 0.299 \\
RT & 0.130 & 0.051 & 2.533 & 0.011 \\
LL & 121.750 & & & \\
AIC & -2.346 & & & \\
SIC & -1.932 & & & \\
\hline \hline
\end{tabular}

Diagnostic tests on standardized and squared standardized residuals

LB (10) $\quad 14.361(0.073)$

$\mathrm{LB}^{2}(10) \quad 7.174(0.709)$

JB $\quad 5.097(0.078)$

$\mathrm{ARCH}(10) \quad 0.689(0.732)$

Note: $*, * *$ and $* * *$ represent the significance at $1 \%, 5 \%$ and $10 \%$ respectively. $\omega$ stands for the constant value of Variance equation, $\alpha, \beta$ and $\gamma$ represent the ARCH term, GARCH term, and leverage term respectively. LL represents the Log-likelihood, $\mathrm{LB}(10)$ and $\mathrm{LB}^{2}(10)$ indicate the Ljung-Box statistics for standardized residuals and squared standardized residuals using 10 lags respectively, $\mathrm{ARCH}$ represents the ARCH-LM test for heteroscedasticity, AIC and SIC are Akaike information Criteria and Schwarz information criteria respectively. Figures in the parenthesis indicate the probability of the test statistic. 
Table 6 exhibits the results of the univariate EGARCH model for the volatility effect from macroeconomic variables to stock returns. A large and significant a1 (ARCH parameter) provides strong support for the presence of previous innovation on stock return volatility whereas a relatively smaller GARCH parameter indicates weak evidence of last period's shock. Concerning the macroeconomic volatility on stock return volatility, the coefficient of IP is found negative but statistically significant, implying that fluctuations in industrial production lead to a decrease in stock return volatility. On the other hand, the coefficients of $C P I, T B$, and RT are positive and statistically significant. These findings manifest that volatility in stock return will be increased when $\mathrm{CPI}, \mathrm{TB}$, and RT become more volatile. Finally, diagnostic tests on standardized and squared standardized residuals show a correctly specified EGARCH model.

Table 7: F-statistics from Multivariate VAR model

\begin{tabular}{|c|c|c|c|c|c|c|}
\hline IP & CPI & M2 & TB & GB & EX & RT \\
\hline \multicolumn{7}{|c|}{ Panel A: Predictive power of stock return volatility } \\
\hline $2.12 * * *$ & 0.84 & 0.49 & $2.08 * * *$ & 1.11 & 1.79 & 0.76 \\
\hline \multicolumn{7}{|c|}{ Panel B: Predictive power of Macroeconomic volatility } \\
\hline $3.37 * *$ & 1.27 & 0.44 & $3.00 * *$ & 0.69 & $2.77 * *$ & 1.11 \\
\hline
\end{tabular}

** $\& * * *$ represent the test statistics are significant at $5 \%$ and $10 \%$ respectively.

Conditional volatility series for stock returns and each of the macroeconomic variables are extracted from the best-fitted model of EGARCH and then multivariate VAR model is implemented on those conditional volatility series to explore the relations between stock return volatility and macroeconomic volatility. Table 7 exhibits the estimates of the multivariate VAR model. It is evident from Panel A of Table 7 that the volatility of IP and TB can influence the stock return volatility at a $10 \%$ level of significance. On the other hand, the variability of stock return is significant in explaining the volatility of IP, TB, and EX which is documented in Panel $B$ of Table 7. So, this study finds a bidirectional causal relationship between DSEX and IP, and TB but a unidirectional causal relationship running from DSEX to EX. 
Ali, M. (2021). Impact of Macroeconomic Variability on the Stock Market Volatility of Bangladesh. BILTURK, The Journal of Economics and Related Studies, 3(2),66-86. doi: 10.47103/bilturk.837413.

Table 8: Variance Decomposition Analysis

Variance Decomposition of Stock returns

\begin{tabular}{|c|c|c|c|c|c|c|c|c|c|}
\hline Period & SE & SR & IP & CPI & M2 & TB & GB & EX & RT \\
\hline 1 & 0.0069 & 100.00 & 0.00 & 0.00 & 0.00 & 0.00 & 0.00 & 0.00 & 0.00 \\
\hline 6 & 0.0114 & 63.18 & 4.60 & 1.47 & 3.67 & 4.37 & 12.39 & 8.93 & 1.39 \\
\hline 12 & 0.0131 & 56.06 & 5.09 & 1.56 & 11.75 & 3.60 & 10.08 & 8.80 & 3.06 \\
\hline 18 & 0.0146 & 48.82 & 6.59 & 2.60 & 9.76 & 3.21 & 8.80 & 14.48 & 5.74 \\
\hline \multicolumn{10}{|c|}{ Variance Decomposition of industrial production } \\
\hline Period & SE & SR & IP & CPI & M2 & TB & GB & EX & RT \\
\hline 1 & 0.0012 & 31.64 & 68.36 & 0.00 & 0.00 & 0.00 & 0.00 & 0.00 & 0.00 \\
\hline 6 & 0.0022 & 20.58 & 27.61 & 3.54 & 14.09 & 8.62 & 1.55 & 18.91 & 5.11 \\
\hline 12 & 0.0027 & 22.73 & 20.63 & 4.68 & 12.61 & 8.69 & 4.59 & 19.62 & 6.45 \\
\hline 18 & 0.0032 & 20.08 & 17.21 & 6.29 & 11.20 & 7.38 & 7.56 & 23.82 & 6.46 \\
\hline \multicolumn{10}{|c|}{ Variance Decomposition of consumer price index } \\
\hline Period & SE & SR & $\mathbf{I P}$ & CPI & M2 & TB & GB & EX & $\mathbf{R T}$ \\
\hline 1 & $4.31 \mathrm{E}-05$ & 8.03 & 3.41 & 88.56 & 0.00 & 0.00 & 0.00 & 0.00 & 0.00 \\
\hline 6 & $7.26 \mathrm{E}-05$ & 13.42 & 1.59 & 62.68 & 6.94 & 1.50 & 6.87 & 5.44 & 1.56 \\
\hline 12 & 0.0001 & 16.96 & 3.33 & 36.33 & 17.82 & 2.16 & 13.75 & 5.23 & 4.41 \\
\hline 18 & 0.0001 & 17.38 & 3.60 & 30.65 & 15.68 & 2.53 & 14.04 & 9.88 & 6.25 \\
\hline \multicolumn{10}{|c|}{ Variance Decomposition of money supply } \\
\hline Period & SE & SR & IP & CPI & M2 & TB & GB & EX & RT \\
\hline 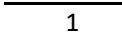 & $8.73 \mathrm{E}-05$ & 0.36 & 1.36 & 6.58 & 91.70 & 0.00 & 0.00 & 0.00 & 0.00 \\
\hline 6 & 0.0001 & 9.35 & 10.74 & 3.14 & 65.88 & 2.08 & 4.04 & 3.72 & 1.05 \\
\hline 12 & 0.0002 & 9.55 & 11.31 & 7.72 & 57.58 & 3.04 & 4.09 & 4.67 & 2.04 \\
\hline 18 & 0.0002 & 13.38 & 9.58 & 6.50 & 47.69 & 3.52 & 4.60 & 10.97 & 3.76 \\
\hline \multicolumn{10}{|c|}{$\begin{array}{l}\text { Variance Decomposition of Treasury bill } \\
\end{array}$} \\
\hline Period & SE & SR & IP & CPI & M2 & TB & GB & EX & RT \\
\hline 1 & 0.0694 & 0.26 & 16.66 & 8.86 & 9.26 & 64.95 & 0.00 & 0.00 & 0.00 \\
\hline 6 & 0.1284 & 3.59 & 11.34 & 18.35 & 13.55 & 33.65 & 8.33 & 8.75 & 2.43 \\
\hline 12 & 0.2037 & 22.43 & 5.92 & 16.74 & 8.65 & 15.48 & 11.79 & 16.72 & 2.27 \\
\hline 18 & 0.3236 & 22.85 & 8.63 & 13.38 & 3.71 & 15.07 & 5.74 & 27.68 & 2.74 \\
\hline \multicolumn{10}{|c|}{ Variance Decomposition of government bond } \\
\hline Period & SE & SR & IP & CPI & M2 & TB & GB & EX & RT \\
\hline 1 & 0.0005 & 2.09 & 7.14 & 8.53 & 2.45 & 1.43 & 78.36 & 0.00 & 0.00 \\
\hline 6 & 0.0011 & 2.55 & 6.18 & 5.35 & 22.02 & 9.75 & 38.76 & 5.89 & 9.51 \\
\hline 12 & 0.0013 & 5.43 & 5.70 & 7.67 & 25.18 & 7.87 & 27.44 & 8.50 & 12.21 \\
\hline 18 & 0.0016 & 15.50 & 3.85 & 7.63 & 16.75 & 5.04 & 17.79 & 20.81 & 12.63 \\
\hline \multicolumn{10}{|c|}{ Variance Decomposition of exchange rate } \\
\hline Period & SE & SR & IP & CPI & M2 & TB & GB & EX & RT \\
\hline 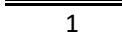 & 0.0002 & 2.12 & 31.66 & 1.48 & 5.99 & 9.99 & 9.10 & 39.66 & 0.00 \\
\hline 6 & 0.0004 & 9.12 & 15.56 & 9.86 & 13.72 & 16.66 & 8.78 & 21.57 & 4.74 \\
\hline 12 & 0.0007 & 55.55 & 5.98 & 5.45 & 7.36 & 5.45 & 8.37 & 8.78 & 3.05 \\
\hline 18 & 0.0009 & 36.74 & 8.36 & 7.78 & 6.24 & 5.90 & 10.32 & 18.44 & 6.23 \\
\hline \multicolumn{10}{|c|}{ Variance Decomposition of remittance } \\
\hline Period & SE & SR & IP & CPI & M2 & TB & GB & EX & RT \\
\hline$\overline{1} 1$ & 0.0009 & 8.92 & 0.33 & 8.59 & 7.89 & 0.42 & 6.50 & 15.58 & 51.77 \\
\hline 6 & 0.0022 & 12.79 & 1.13 & 30.26 & 2.50 & 1.21 & 5.52 & 5.37 & 41.22 \\
\hline 12 & 0.0037 & 29.59 & 2.66 & 15.40 & 5.44 & 0.93 & 9.02 & 12.16 & 24.79 \\
\hline 18 & 0.0046 & 21.50 & 2.11 & 11.45 & 9.43 & 1.22 & 7.55 & 21.17 & 25.67 \\
\hline
\end{tabular}

Cholesky ordering: SR, IP,CPI,M2,TB,GB, EX, RT 


\subsection{Variance Decomposition Analysis}

Having established the factors that significantly affect the stock return volatility as well as having identified the causal relationships, it is imperative to know what proportion of stock return volatility is explained by the conditional volatility of each of the individual macroeconomic forces and vice versa. To address this issue, 18month variance decomposition is estimated by extracting the conditional variance from the best-fitted EGARCH model.

Variance decomposition functions split the forecast error variance for each of the individual variables into parts to uncover the effect and magnitude of exogeneity of the variables in the dynamic structure of VAR. It explains the percentage of stock return volatility due to the volatility of each of the individual macroeconomic variables and vice versa. The results of the variance decomposition are documented in Table 8 for four different time horizons. It is evident from Table 8 that the variation of stock returns volatility is mainly due to the volatility of macroeconomic variables. More particularly, almost 65 percent of the stock market volatility can be explained by the macroeconomic volatility. Table 8 shows that EX plays an important role as a dominant source of stock return volatility followed by GB and IP. On average, other macroeconomic variables namely $\mathrm{CPI}, \mathrm{M} 2, \mathrm{~TB}$, and RT share equal contributions in explaining DSEX volatility. Therefore, these findings suggest that macroeconomic volatility plays a major role in detecting and forecasting future volatility of stock returns.

Variance decomposition can also explain the effect and extent of macroeconomic volatility resulting from the variability in the stock return volatility. This analysis suggests mixed results. The volatility of most of the selected macroeconomic variables except IP, TB, and GB is mainly influenced by the DSEX volatility. In the short run i.e., at the first and sixth month, a lion portion of the variability of macroeconomic variables is due to their own shocks whereas volatility of stock returns greatly influence the variability in the macroeconomic fundamentals in the long run (i.e., at 12th and 18th month ahead). These findings signify that influence of stock returns volatility increase on the macroeconomic volatility in the longer time horizon. Therefore, these findings imply that both stock returns and macroeconomic volatility influence each other to some extent.

\subsection{Impulse Response Analysis}

This study estimates 10-month impulse response functions (IRFs) which are depicted in Figure 1. The middle thick lines represent impulse response whilst standard error bands are shown by dotted lines. Figure 1 demonstrates that stock return is very much sensitive to one standard deviation shock to industrial production. It signifies that the economic activities of Bangladesh highly influence the stock market of Bangladesh. Similarly, responses of money supply and exchange rates are diverse in the volatility of the Bangladesh stock market. These findings imply that an increase in money supply and exchange rates create inflationary 
Ali, M. (2021). Impact of Macroeconomic Variability on the Stock Market Volatility of Bangladesh. BILTURK, The Journal of Economics and Related Studies, 3(2),66-86. doi: 10.47103/bilturk.837413.

pressure in the economy which ultimately influences the earnings and profitability of the firms. On the other hand, Treasury bill shock is found to be positive. This result implies that stock return volatility increases with the increase in the volatility of the Treasury bill. Therefore, macroeconomic shocks create risk and uncertainty in the economy which in turn increases the stock market volatility.

Figure 1: Impulse response Analysis

Response to Cholesky One S.D. Innov ations \pm 2 S.E.
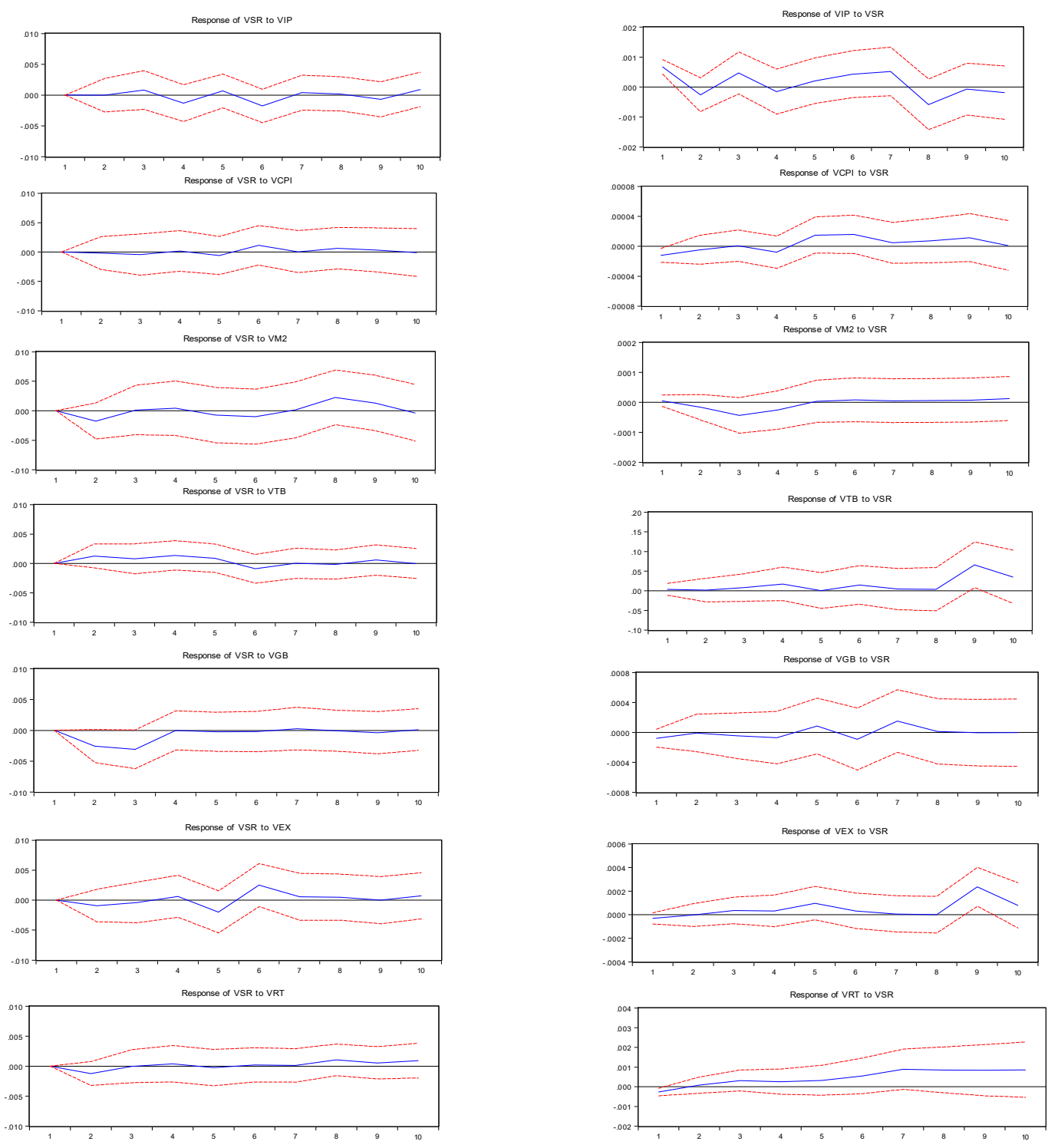


\section{Conclusion}

This study investigates the impact of macroeconomic variability on stock market volatility in Bangladesh by using three steps of analysis. At the first stage, we employed the EGARCH model and find volatility persistence in stock returns and all the growth series of macroeconomic variables except for IP and GB. In the second phase, the volatility effect of macroeconomic forces on stock return is estimated by using the most recent standardized squared residuals of macroeconomic fundamentals as exogenous variables in the conditional variance equation of stock returns. The results evident that volatility of the stock returns increases with the volatility increased in CPI, TB, and RT but fluctuations in IP lead to a decrease in stock return volatility. Further, the Multivariate Vector Auto Regression (VAR) model along with Variance Decomposition Analysis is used in the third stage to examine the possible interaction between macroeconomic forces and stock price. The results of the study report that the volatility of IP and TB can significantly influence the stock return volatility. Moreover, stock return volatility can significantly explain the volatility of IP, TB, and EX.

Results of this study have significant inference for the market analyst. Since there is an interconnection between the stock market and the macroeconomic environment of Bangladesh, market participants should closely monitor the macroeconomic environment in making investment decisions as well as formulating hedging and portfolio diversification strategies. Moreover, financial regulators and policymakers should consider macroeconomic fundamentals in modeling and executing the economic policy of Bangladesh. 


\section{References}

Abbas, G., Hammoudeh, S., Shahzad, S. J. H., Wang, S., \& Wei, Y. (2019.) Return and volatility connectedness between stock markets and macroeconomic factors in the G-7 countries. Journal of Systems Science and Systems Engineering, 28, 1-36.

Adjasi, C. K. D. (2009). Macroeconomic uncertainty and conditional stock-price volatility in frontier African Markets: Evidence from Ghana. The Journal of Risk Finance, 10(4), 333-349.

Aliyu, S. U. R. (2012). Does inflation have an impact on stock returns and volatility? Evidence from Nigeria and Ghana. Applied Financial Economics, 22, 427-435.

Asgharian, H., Hou, A. J., \& Javed, F. (2013). The importance of the macroeconomic variables in forecasting stock return variance: A GARCH-MIDAS approach. Journal of Forecasting, 32, 600-612.

Baroian, E. (2014). Can macroeconomic volatility affect stock market volatility? The case of 5 central and eastern European countries. Romanian Journal of Fiscal Policy, $5(2), 41-55$.

Beetsma, R., \& Giuliodori, M. (2012). The changing macroeconomic response to stock market volatility shocks. Journal of Macroeconomics. 34(2), 281-293.

Berndt, E., Hall, B., Hall, R., \& Hausman, J. (1974). Estimation and inference in nonlinear structural models. Annals of Social Measurement, 3, 653-665.

Bollerslev, T., \& Wooldridge, J. M. (1992). Quasi-maximum likelihood estimation and inference in dynamic models with time-varying covariances. Econometric Reviews, 11(2), 143-172.

Chen, N., Roll, R., \& Ross, S. A. (1986). Economic forces and the stock market. Journal of Business, 59, 383-403.

Chen, J., Xiong, X., Zhu, J., \& Zhu, X. ( 2017). Asset prices and economic fluctuations: the Implications of stochastic volatility. Economic Modelling, 64, 128-140.

Chowdhury, S. S. H., \& Rahman, M. A. (2004). On the empirical relation between macroeconomic volatility and stock market volatility of Bangladesh. The Global Journal of Finance and Economics, 1(2), 209-225.

Corradi, V., Distaso, W., \& Mele, A. (2013). Macroeconomic determinants of stock volatility and volatility premiums. Journal of Monetary Economics, 60, 203-220.

Cutler, D. M., Poterba, J. M., \& Summers, L. H. (1989). What moves stock prices? Journal of Portfolio Management, 15, 4-12. 
Dayıoğlu, T., \& Aydın, Y. (2019). Relationship between the Volatility of Stock Returns and the Volatility of Macroeconomic Variables: A Case of Turkey. American Journal of Theoretical and Applied Business. 5 (2), 40-46.

Dickey, D. A., \& Fuller, W. A. (1981). Likelihood ratio statistics for autoregressive time series with a unit root. Econometrica, 49, 1057-1072.

Erdem, C., Arslan, C. K., \& Erdem, M. S. (2005). Effects of macroeconomic variables on Istanbul stock exchange indexes. Applied Financial Economics, 15(14), 987-994.

Fama, E. F. (1981). Stock returns, real activity, inflation, and money. American Economic Review, 71(4), 545-565.

Fama, E. F. (1990). Stock returns, expected returns and real activity. Journal of Finance, 45(4), 1089-1108.

Fernando, A. (2018). Macroeconomic Impact on Stock Market Returns and Volatility: Evidence from Sri Lanka. Business and Economics Journal, 9(4),1-15. doi:10.4172/2151-6219.1000379

Garza-Garcia, J. G., \& Yue, Y. (2010). International determinants of stock market performance in China: A cointegration approach. Working Paper Series (ISSN 20411596), Paper Number: 03/10, Centre for Global Finance, Bristol Business School, University of the West of England.

Hamao, Y., Masulis, R. W., \& Ng, V. (1990). Correlations in price changes and volatility across international stock markets, Review of Financial Studies, 3, 281307.

Hsing, Y. (2011). Impacts of Macroeconomic Variables on the Stock Market in Bulgaria and Policy Implications. Journal of Economics and Business, 14, 2, 41-53.

Hsing, Y., \& Hsieh, W. (2012). Impacts of macroeconomic variables on the stock market index in Poland: new evidence. Journal of Business Economics and Management, 13(2), 334-343.

Jain, A., \& Biswal, P. C. (2016). Dynamic linkages among oil price, gold price, exchange rate, and stock market in India. Resource Policy, 49, 179-185.

Kabir, S. H., Bashar, O. K. M. R., \& Masih, M. M. (2014). Is domestic stock price cointegrated with exchange rate and foreign stock price? Evidence from Malaysia. The Journal of Developing Areas, 48 (3), 285-302.

Kan, Y. Y. \& Lim, G. C. (2015). Structural break and cointegration in Malaysian stock market. International Proceedings of Economics Development and Research, $84,25-42$.

Kanas, A., \& Kouretas, G. (2001). Volatility spillovers between black market and official markets for foreign currency in Greece, Journal of Financial Research, 24, 443-461. 
Karim, B. A., Sea, L. P., \& Karim, Z. A. (2014). The impact of macroeconomic volatility on the Indonesian stock market volatility. International Journal of Business and Technopreneurship, 4(3), 467-476.

Kumari, J., \& Mahakud, J. (2015). Relationship between conditional volatility of domestic macroeconomic factors and conditional stock market volatility: Some further evidence from India. Asia-Pacific Financial Markets, 22, 87-111.

Kwiatkowski, D., Phillips, P. C. B., Schmidt, P., \& Shin, Y. (1992). Testing the null hypothesis of trend stationanity. Journal of Econometrics, 54, 159-178.

Mazuruse, P. (2014). Canonical correlation analysis: Macroeconomic variables versus stock returns. Journal of Financial Economic Policy, 6(2), 179-196.

Mittnik, S., Robinzonov, N., \& Spindler, M. (2015). Stock market volatility: Identifying major drivers and nature of their impact. Journal of Banking and Finance, 58, 1-14.

Nelson, D. B. (1991). Conditional heteroskedasticity in asset returns: A new approach. Econometrica 59(2), 347-370.

Nguyen, T. \& Ngo, C. (2014). Impacts of the US macroeconomic news on Asian stock markets. The Journal of Risk Finance, 15(2), 149-179.

Nikmanesh, L. \& Nor, A. H. S. M. (2016). Macroeconomic determinants of stock market volatility: An empirical study of Malaysia and Indonesia. Asian Academy of Management Journal, 21(1), 161-180.

Park, S. Y., Ryu, D. \& Song, J. (2017). The dynamic conditional relationship between stock market returns and implied volatility. Physica A, 482, 638-648.

Paye, B. S. (2012). 'Deja Vol': Predictive regressions for aggregate stock market volatility using macroeconomic variables. Journal of Financial Economics, 106, 527 546

Roll, R. (1988). R². Journal of Finance, 43, 541-566.

Schwert, G. W. (1989). Why does stock market volatility change over time? Journal of Finance, 44, 1115-1153.

Sims, C. (1980). Macroeconomics and reality. Econometrica, 48, 1-48.

Susmel, R., \& Engle, R. F. (1994). Hourly volatility spillovers between international equity markets, Journal of International Money and Finance, 13(1), 3-25.

Tangjitprom, N. (2012). The review of macroeconomic factors and stock returns. International Business Research, 5(8), 107-115. 
Ali, M. (2021). Impact of Macroeconomic Variability on the Stock Market Volatility of Bangladesh. BILTURK, The Journal of Economics and Related Studies, 3(2), 66-86. doi: 10.47103/bilturk.837413.

Tokmakcioglu, K., \& Tas, O. (2014). Stock market and macroeconomic volatility comparison: An US approach. Quality and Quantity, 48, 217-224.

Zakaria, Z., \& Shamsuddin, S. (2012). Empirical evidence on the relationship between stock market volatility and Macroeconomic volatility in Malaysia. Journal of Business Studies Quarterly, 4(2), 61-71. 